\title{
Ondansetron, a 5-HT3 antagonist, improves cerebellar tremor
}

\author{
G P A Rice, J Lesaux, P Vandervoort, L Macewan, G C Ebers
}

Multiple Sclerosis Clinic, Department of Clinical Neurological

Sciences, London Health Sciences Centre, University Campus, 339

Windermere Road, London, Ontario, Canada N6A 5A5

G P A Rice

J Lesaux

$P$ Vandervoort

L Macewan

G C Ebers

Correspondence to:

Dr G P A Rice, Multiple Sclerosis Clinic, Departmen of Clinical Neurological Sciences, London Health Sciences Centre, University Campus, 339 Windermere Road, London, Ontario, Canada N6A 5A5.

Received 24 June 1996 and in final revised form 7 November 1996

Accepted 25 November 1996

\section{Abstract}

It has been previously shown that ondansetron, a 5-HT3 antagonist, can ameliorate vertigo in patients with acute brainstem disorders. A coincidental benefit was the improvement of cerebellar tremor in some patients with both vertigo and tremor. To further evaluate this effect, a placebo controlled, double blind, crossover study was conducted of a single dose of intravenous ondansetron in 20 patients with cerebellar tremor caused by multiple sclerosis, cerebellar degeneration, or drug toxicity. The principal outcome measures were the change in blind assessment of a writing task (spiral copying) and the timed completion of a nine hole peg test. Thirteen of 19 patients were deemed to have improved spiral copying after treatment with ondansetron when compared with baseline performance. One patient had a better response to the placebo compared with baseline perfor- mance $(P=0 \cdot 00024)$. Patients completed the nine hole peg test in less time after ondansetron than after placebo $(\mathbf{P}=$ $0 \cdot 08)$. Twelve patients thought that their tremor was functionally improved with the ondansetron treatment. None thought that the placebo gave improvement $(P=$ 0.00098).

The efficacy of orally administered ondansetron in tremor control is currently under study.

(F Neurol Neurosurg Psychiatry 1997;62:282-284)

Keywords: cerebellar tremor; ondansetron; 5-hydroxytryptophan-3 antagonists

In a previous open label study we showed that ondansetron, a 5-hydroxytryptophan-3 (5HT3) antagonist, was effective in controlling vertigo in patients with acute brainstem disor-

\begin{tabular}{|c|c|c|c|c|c|c|c|c|c|}
\hline \multirow{2}{*}{$\begin{array}{l}\text { Patient } \\
\text { No }\end{array}$} & \multirow[b]{2}{*}{ Disease } & \multirow{2}{*}{$\begin{array}{l}\text { Tremor type } \\
\text { and clinical } \\
\text { findings }\end{array}$} & \multirow{2}{*}{$\begin{array}{l}\text { Prior } \\
\text { treatment }\end{array}$} & \multicolumn{2}{|c|}{ Spiral copying } & \multicolumn{2}{|c|}{ Subjective response } & \multicolumn{2}{|c|}{$\begin{array}{l}\text { Time to complete nine } \\
\text { hole peg test }\end{array}$} \\
\hline & & & & Placebo & Drug & Ondansetron & Placebo & Placebo & Ondansetron \\
\hline 1 & $\begin{array}{l}\text { Cerebellar } \\
\text { degeneration }\end{array}$ & $\begin{array}{l}\text { Intention, } \\
\text { postural }\end{array}$ & Clonazepam & 0 & +++ & ++ & 0 & 101 & 85 \\
\hline 2 & $\begin{array}{l}\text { Cerebellar } \\
\text { degeneration }\end{array}$ & Intention & None & 0 & ++ & +++ & 0 & 62 & 45 \\
\hline 3 & Cerebellar & & & & & & & & \\
\hline 4 & $\begin{array}{l}\text { degeneration } \dagger \\
\text { Lithium }\end{array}$ & $\begin{array}{l}\text { Intention } \\
\text { Intention }\end{array}$ & $\begin{array}{l}\text { Clonazepam } \\
\text { Clonazepam }\end{array}$ & $\mathrm{NT}$ & NT & + (dysarthria) & NT & NT & NT \\
\hline & intoxication & Dysarthria & Valproate & 0 & 0 & 0 & 0 & 47 & 55 \\
\hline 5 & MS & Intention & Clonazepam & 0 & +++ & +++ & 0 & 84 & 70 \\
\hline 6 & MS & Intention & Clonazepam & 0 & +++ & +++ & 0 & NT & NT \\
\hline 7 & MS & Intention & None & 0 & + & ++ & 0 & 37 & 29 \\
\hline 8 & MS & Intention & None & 0 & + & + & 0 & NT & NT \\
\hline 9 & MS & Intention & None & 0 & ++ & ++ & 0 & NT & NT \\
\hline 10 & MS & Intention & None & 0 & + & ++ & 0 & 140 & 110 \\
\hline 11 & MS & Intention & None & 0 & +++ & $+t$ & 0 & NT & NT \\
\hline 12 & MS & Intention & None & + & + & 0 & 0 & 78 & 63 \\
\hline 13 & MS & Intention & None & 0 & ++ & + & 0 & NT & NT \\
\hline 14 & MS & Intention & None & 0 & 0 & 0 & 0 & 157 & 155 \\
\hline 15 & MS & Intention & None & 0 & + & 0 & 0 & 65 & 55 \\
\hline 16 & MS & Intention & None & 0 & 0 & 0 & 0 & 65 & 48 \\
\hline 17 & MS & Intention & None & 0 & 0 & 0 & 0 & NT & NT \\
\hline 18 & MS & $\begin{array}{l}\text { Intention/ } \\
\text { Dysarthria }\end{array}$ & None & 0 & + & 0 & 0 & 160 & 180 \\
\hline 19 & MS & Intention/ & & & & & & & \\
\hline & & Dysarthria & None & 0 & ++ & + & 0 & NT & NT \\
\hline 20 & MS & Intention & None & 0 & 0 & 0 & 0 & 54 & 57 \\
\hline $\begin{array}{l}\text { Ratios or } \\
\text { means (SEM) }\end{array}$ & & & & $1 / 19$ & $14 / 19$ & $12 / 20$ & $0 / 19$ & $87(12) \mathrm{s}$ & $79(12) \mathrm{s}$ \\
\hline
\end{tabular}

* The figure shows the spiral copying of this patient.

+ The development of dystonia in this patient dissipated patient enthusiasm to continue in the study.
$\mathrm{NT}=$ Not tested (generally because patients could not complete the test). Improvement was measured on a simple ordinal scale: $0=$ none, $+=$ a little, $++=$ NT = Not tested (generally because patients could not complete 
Spiral copying performance for patient 1

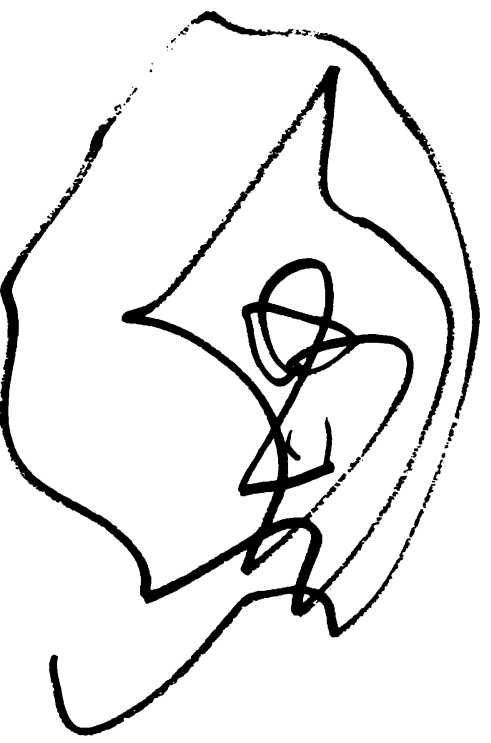

Baseline

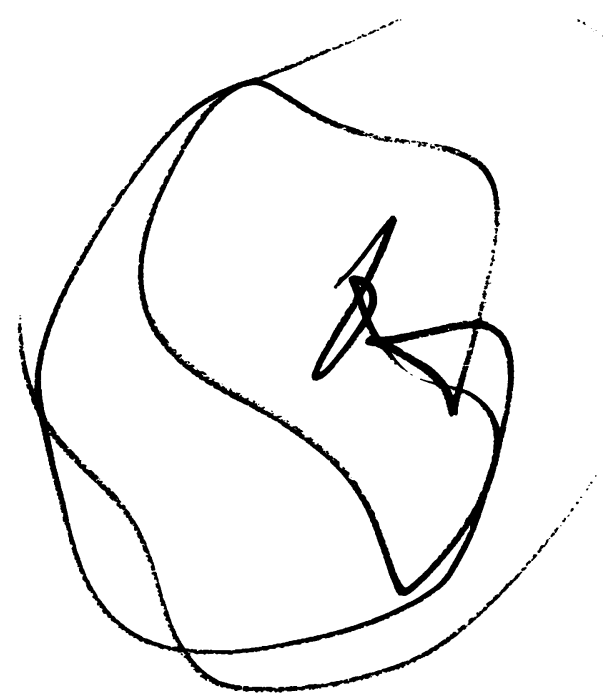

Placebo

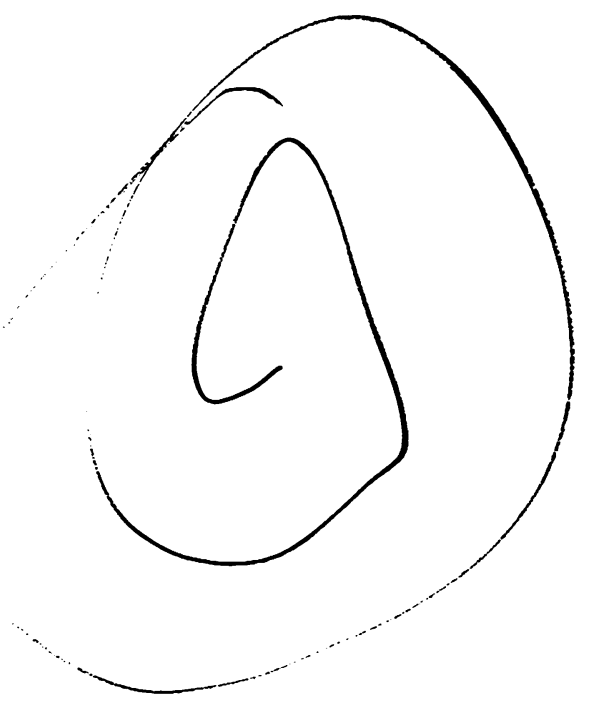

Ondansetron ders including multiple sclerosis and brainstem strokes. ${ }^{1}$ Some patients with concomitant cerebellar tremor volunteered that tremor improved. This serendipitous observation prompted an efficacy finding study in a group of patients in whom tremor, but not vertigo, was a major clinical feature.

\section{Patients and methods}

Twenty patients with moderate to severe cerebellar tremor (Kurtzke functional cerebellar score $\geqslant 3$ ) were recruited from the Department of Clinical Neurological Sciences. In most patients, the tremor was based on cerebellar involvement from multiple sclerosis; three had familial degenerative disorders involving the cerebellum and one had residual ataxia complicating lithium intoxication. The table outlines the clinical information and prior treatment of the patients. Patients were excluded from the study if they had had treatment with ondansetron or if they were unwilling to fully participate in both limbs of the trial. A signed, informed consent was obtained before initiation of study procedures. Alcoholic patients were excluded. Patients were not receiving concomitant medications such as clonazepam, isoniazid, carbamazepine, or valproic acid.

Patients were randomly assigned to receive intravenous ondansetron $(8 \mathrm{mg})$ or a placebo, consisting of normal saline. The drug was given by intravenous bolus injection. Peak serum concentrations are reached within 15 minutes and the drug has a half life of three to four hours. Patient assessments were made within the first 90 minutes of treatment. Patients were given the alternate agent on a subsequent day, generally a week later. The patients and the evaluators were blinded throughout the study.

The principal outcome measures were the change in performance on writing tasks (spiral copying), determined by comparing the change from a baseline attempt to the performance one hour later.

A second outcome measure was determined by the time to complete a nine hole peg test. Only 12 patients had sufficient coordination to complete this test. These clinical outcomes were measured at a baseline and at one hour after the infusion. The times for each arm were summed after a single trial. Copying exercises were performed first, followed by the peg test.

\section{Results}

The table shows the patient profiles and clinical outcomes.

A blind evaluator group (GCE, JL, PV) scored the spirals on an ordinal scale $(0=$ no difference apparent, $+=$ mild improvement, $++=$ moderate/marked improvement). Concordance among evaluators was excellent. The group deemed that spiral copying after ondansetron treatment, compared with baseline, was superior in 13 of the 19 patients. Only one patient was better after placebo 
treatment. The difference was significant $(P=$ 0.00024; two tailed McNemar's test).

The completion of a timed task, the nine hole peg test, was also improved in patients who received ondansetron. The mean time for the completion of this task was 79 seconds in patients treated with ondansetron and $87 \mathrm{sec}$ onds in patients treated with placebo $(P=$ 0.08 ; Wilcoxon rank sum; two tailed test for paired data).

Patients could not perceive any immediate side effects from the treatment. One patient noticed a headache after injection of placebo and one patient treated with ondansetron developed a foot dystonia which resolved spontaneously within 30 minutes. Short lasting dystonia has been described rarely in patients treated with ondansetron.

At the end of the study patients were asked if they could perceive a functional difference in the two treatment arms. Based on efficacy, 12 of 20 identified that ondansetron was superior to placebo for tremor control; the remaining patients could not perceive a difference. None thought that the placebo was better $(\mathbf{P}=$ 0.00098; two tailed McNemar's test,). One patient was identified as having a mild improvement in writing tasks by the blind evaluator, but the patient did not think that the change was significant.

The figure shows the performance of one patient.

\section{Discussion}

A role for serotonin in the treatment of cerebellar tremor is suggested by these findings and others. The cerebellum has a serotoninergic innervation. ${ }^{2}$ In some animal models of cerebellar ataxia, such as that caused by thiamine deficiency, there is enhanced turnover of serotonin and its metabolites. ${ }^{3}$ In some degenerative disorders, such as olivopontocerebellar degeneration, the concentration of 5-HT metabolites is increased in the striatum. ${ }^{4}$ In a group of patients with various acquired and familial cerebellar disorders, Trouillas showed that tremor was improved by $5-\mathrm{HT}$ in combination with benzeraside. ${ }^{5}$ In subsequent trials, the beneficial effect of the levorotatory form of 5-HT has been shown in patients with Friedreich's ataxia ${ }^{6}$ but not in another trial with patients with miscellaneous cerebellar disorders. ${ }^{7}$ Tremor is a side effect of treatment with selective serotonin reuptake inhibitors and this complication can be disabling. ${ }^{8}$

The identification of ondansetron as an agent which could ameliorate both vertigo, with attendant nausea and vomiting, and cerebellar tremor is reminiscent of a classic observation. McLellan et al described a family in which autosomal dominant cerebellar ataxia was associated with congenital inability to vomit. ${ }^{9}$ Members of this family could predict who would get the ataxia later in life by identification in childhood of those who were unable to vomit. The serotonin axis might be central to this intriguing finding.

Most physicians would concede that treatment of cerebellar tremor is difficult. There have been reports of limited success with clonazepam, carbamazepine, ${ }^{10}$ and isoniazid. ${ }^{11}$ The identification of a therapeutic response to ondansetron is worthy of further study. The serotonin axis could prove to be fertile ground for the pharmacological study of tremor.

Five patients in the original report have continued to take ondansetron on a daily basis because they derived a clinically meaningful benefit. Withdrawal of the medication has aggravated the tremor. A clinical trial is underway to assess the efficacy and durability of oral ondansetron in the management of tremor.

We acknowledge the support of the patients who participated in this trial. At our request the drug was provided by Glaxo Wellcome Canada.

1 Rice GPA, Ebers GC. Ondansetron for intractable vertigo complicating acute brainstem disorders. Lancet 1995 345:1182-3.

2 Trouillas $P$. The cerebellar serotoninergic system and its possible involvement in cerebellar ataxia. Can 7 Neurol Sci 1993;(suppl 3):78-82.

3 VanWoert MH, Plaitakis A, Hwang EC, Berl S. Effect of thiamine deficiency on brain serotonin turnover. Brain Res 1979;138:103-10.

4 Kish SJ, Robitaille Y, El-Awar M. Striatal monoamine neurotransmitters and metabolites in dominant inherited rotransmitters and metabolites in dominant inherited
olivopontocerebellar atrophy. Neurology 1992;42:1573-7.

5 Trouillas P. Regression of cerebellar syndrome with longTrouillas $P$. Regression of cerebellar syndrome with longterm administration of 5-HTP or the combin
benserazide. Ital $₹$ Neurol Sci 1984;5:253-66.

6 Trouillas P, Serratrice G, Laplane D, Rascol D. Levorotary form of 5-hydroxytryptophan in Friedreich's ataxia. Arch Neurol 1995;52:456-60.

7 Wessel K, Hermsdorfer J, Herzog T, et al. Double-blind, crossover study with levo-rotatory form of hydroxytryptophan in patients with degenerative cerebellar diseases. Arch Neurol 1995;52:451-5.

8 Haenel T, Stockli HR, Truog P. A case of rare side effects of certain antidepressive drugs. Nervenarzt 1995;66:70-2.

9 McLellan DL, Park DM. Failure to vomit in hereditary ataxia. Report of a family. Neurology 1973;23:725-8.

10 Sechi GP, Zuddas M, Piredda M, et al. Treatment of cerebellar tremors with carbamazepine: a controlled trial with bellar tremors with carbamazepine: a controlled t
long term follow-up. Neurology 1989;39:1113-5.

long term follow-up. Neurology 1989;39:1113-5.
11 Hallett $M$, Lindsay JW, Adelstein BD, Riley PO. Controlled trial of isoniazid in severe postural cerebellar tremor in multiple sclerosis. Neurology 1985;35:1374-8. 